This is a peer-reviewed, accepted author manuscript of the following research article: Al-Turaihi, A., Mehmanparast, A., Brennan, F., \& Soyama, H. (2019). Cavitation shotless peening effects on fatigue crack growth behaviour under bending loads. Material Design \& Processing Communications, [88]. https://doi.org/10.1002/mdp2.88

\title{
Cavitation shotless peening effects on fatigue crack growth behaviour under bending loads
}

\begin{abstract}
The effects of partial surface shotless peening on the fatigue crack growth behaviour of a ferritic steel have been experimentally investigated in this paper. Seven fatigue tests were performed on 4-point bend specimens fabricated from Optim700QL high strength steel. Three distinct extents of partial cavitation shotless peening, with respect to the crack tip and specimen symmetry line, were applied on the specimen geometry. Alternating Current Potential Difference (ACPD) was used to measure and monitor the crack depth during fatigue tests. The tests on partially surface peened specimens were conducted under two different load levels. The fatigue crack growth results from these experiments on partially peened specimens have been presented and compared with the results from an additional test on an unpeened specimen. The results show that the residual stress distribution fields formed due to the peening process play a significant role in the fatigue crack shape evolution, crack retardation and crack propagation behaviour of the material.
\end{abstract}

Keywords: Fatigue, Crack shape evolution, ACPD, Cavitation shotless peening, High strength steel, Surface defect, Residual stress

\section{Introduction}

Structural components' lifetime, when such components have been made to face cyclic loading conditions, is notably affected by various factors, including the operation environment, preexisting flaws and defects, effective stresses, and the number of instances of fatigue cycles. The effective stresses highlighted in structures and components could encompass various residual and applied stresses, all caused throughout fabrication, such as during bending, surface treatment and welding, for example. Importantly, residual stresses can prove to be advantageous, i.e. compressive, or otherwise may be negative, i.e. tensile; this ultimately comes down to magnitude and pattern. Importantly, any presentation of compressive residual stresses into structures and components is recognised as being an effective instrument when seeking to enhance the overall mechanical aspects and fatigue life of any engineering structures and components. 
The majority of failures witnessed in the fatigue arena, specifically across engineering components, are seen to be instigated as a result of surface defects and/or cracks, with the remaining lifetime notably influenced by the resistance of the material in relation to the growth of surface cracks [1]. Accordingly, before operation, surface treatment plays a key role in extending the life of structural components, as well as in the overall fatigue resistance of such. A number of different research have been completed in recent times with the aim of examining the influential factors underpinning residual stresses, as induced into structural components as a result of surface treatment, and on the subsequent fatigue behaviour of engineering components. In this vein, other researchers analysed the overall effects of cold rolling on the development and change of crack shape in specific consideration to BS7191 Grade 275A mild steel plates; the work established that crack initiation, crack propagation and fatigue life generally were significantly influenced by residual stresses [2]-[4]. Furthermore, the residual stress intensity factor was applied in the study of Lados \& Apelian in an effort to estimate the residual stress distribution in a compact tension, $\mathrm{C}(\mathrm{T})$, fracture mechanics specimen geometry composed of Si-Mg alloys before testing [5]. Moreover, the influences of initial residual stresses in regards scratch/dent type surface anomalies were examined by Doremus et al. in specific consideration to fatigue crack initiation and propagation in the case of Direct Aged (DA) Inconel 718 alloy, with the study establishing that the residual stress fields are of notable impact on crack shape evolution, which subsequently results in the creation of ear-shaped cracks [6].

The effects of cavitation shotless peening was examined with various materials, including Titanium [7], Carbonised steel [8], Stainless steel [9] and Aluminium [10], with the researchers establishing that a material's fatigue strength can be reinforced through shotless peening [11] [7]. In addition, it was also determined that micro-strains could also be relieved as a result of cavitation shotless peening, notably through introducing macro-strain in the case of a polycrystalline metal surface [12]. The scholars further recognised that the formation of plastic deformation beneath the surface was owing to the effects of Cavitation in the case of carbon steel specimens [13].

Despite the fact that some very small-scale and restricted works have been carried out in order to analyse the effects of cavitation shotless peening on metallic materials' recognised structural integrity, it remains that only very minimal attention has been directed towards the effects of cavitation shotless peening on Fatigue Crack Growth Behaviour in the case of high-strength 
steels, specifically when aiming to extend the use of such surface treatment techniques to wider arenas, such as in the case of offshore wind and offshore oil and gas. Accordingly, in this particular work, focus is centred on the completion of an experimental investigation in order to analyse the effect of partial surface treatment in relation to the progression and propagation of surface crack in the case of a high-strength ferritic steel. The findings garnered as a result of the experiments are detailed and considered in regards the overall efficiency of the partial surface shotless peening approach in relation to the delay of crack growth and the extension of fatigue life in the case of structures and components of engineering.

\section{Experimental Details}

\section{Material and Specimen Design}

In this work, the material utilised for examination was the high-strength ferritic steel referred to as Optim700QL [14]. In the completion of this work, 4-point bend specimens underwent machining from an Optim $700 Q L$ plate. As can be seen detailed in the Figure 3, the dimensions of the 4-point bend specimens were as follows: $330 \mathrm{~mm}$ length, $100 \mathrm{~mm}$ width and $25 \mathrm{~mm}$ thickness. As also detailed in the figure, the centre of the 4-point bend specimen was exposed to the machining of a semi-circular starter notch, notably with a radius equating to $5 \mathrm{~mm}$. Importantly, partial peening was applied to the specimens through the use of cavitation shotless peening for $120 \mathrm{~mm}$. This was applied in an axial direction across the specimen's geometry.

A total of seven (7) test specimens, each of which with its own individual degree of cavitation shotless peening area, i.e. 10, 20 and $30 \mathrm{~mm}$ gap within the unpeened area (see the 'A' dimension in Figure 3), underwent preparation and testing. The tests carried out across the specimens with varying degrees of partially peened areas and their corresponding loading conditions can be seen detailed in the table below. The loads applied for the tests were selected with consideration to the yield strength of the material, as well as the Stress Concentration Factor (CSF) with the aim of ensuring any notable plasticity at the crack tip would be circumvented. For this particular geometry, the SCF-related solutions can be identified in Peterson's Handbook [15]; the specimen dimensions' SCF values, as utilised in this work, can be found detailed in 2.9 .

\section{Details Pertaining to Partial Surface Cavitation Shotless Peening}


An innovative approach to surface modification was presented, which utilised a cavitation jet process, notably controlled by various parameters, including nozzle size and upstream pressure [9][10]. The process centres on creating a compressive residual stress field in the treated surface; this is then recognised as cavitation shotless peening. A rationale underpinning the process being referred to as shotless is owing to the fact that peening is carried out by the cavitating jet without any shots required (see Figure 1)(a)). Importantly, cavitation may be described as a change in status from liquid to gas, which is achieved through reducing the liquid's static pressure until the point of saturated vapour pressure as a result of a greater degree of flow velocity, and the identification of a collapsed cavitation bubble when static pressure is increased through flow velocity decrease. Upon the collapse of the cavitation bubble, there is the deformation of some of the bubble; micro-jets are created as a result (see Figure 1(b)). The micro-jet's speed is approximately $1500 \mathrm{~m} / \mathrm{s}$, with this speed potentially able to cause deformation in the plastic on the surface of the metal. It can be seen that, upon visual examination, a good surface finish can be achieved when implementing cavitation shotless peening; in such a case, it is difficult to identify those regions that have been exposed to peening and those that have not. In this regard, Figure 2 details the surface finish of the high-strength ferritic steel utilised in this case, namely $\operatorname{Optim} 700 Q L$, as treated through cavitation shotless peening and shot peening.

\section{a. Peened Specimens: Measurements of Residual Stress}

Residual stresses, which may be recognised as embedded local stresses that behave on the component in an independent manner when compared with the global loading conditions, can be incorporated into engineering structures and components throughout the process of fabrication. Residual stresses are created as a result of the introduction of the local plastic strain region in the material surrounded by an elastic region. Such residual stresses have the potential to notably influence the growth behaviour of the crack, potentially resulting in engineering structures and components demonstrating failure; this then warrants consideration and life evaluation in terms of structural integrity [16]. Accordingly, in the current paper, it is expected that residual stresses will be presented within the specimens owing to partial surface peening. Accordingly, there was the application of an incremental hole drilling approach with the aim of calculating the residual stress profile in the test specimens. ICHD has been used to measure residual stress distribution and the residual stress has been calculated by using a nonuniform 
stress integral method. The ICHD test has been standardized for a clear procedure for stress calculation and ASTM E837 standard contains the procedure to conduct residual stress measurement[17]. An example of the residual stress measurement stemming from the A20 specimen is provided here. Importantly, the measurement of the residual stresses has been carried out at various points so as to ensure a residual stress distribution map is provided in the specimen, as detailed in Figure 3. Furthermore, the measurement of the residual stress distribution was carried out across both transverse and longitudinal directions with regards the loading axis. With this noted, the residual stress profile at one of the chosen points, notably within the peened region, can be seen detailed in Figure 4.

In the A20 specimen, the three-dimensional demonstration pertaining to the distribution of the residual stress, notably along the transverse and longitudinal directions, can be seen depicted in Figure 5 and Figure 6, respectively. As is apparent, dominantly compressive residual stresses can be witnessed across 4-point bend specimens in both directions as a result of the cavitation shotless peening. At the peened area, the minimum peak residual stress was recognised as being in the region of $-500 \mathrm{MPa}$ and $-400 \mathrm{MPa}$ in longitudinal and transverse directions, respectively; on the other hand, as a result of force equilibrium, a number of different tensile residual stresses were identified in the remainder of the specimen. In the case of the sample, the compressive residual stresses are recognised as being up to $0.4 \mathrm{~mm}$ depth. Furthermore, in the region of the A20 specimen sample that was not peened, the residual stresses underwent measurement, with tensile stresses of approximately $200 \mathrm{MPa}$ and $100 \mathrm{MPa}$ identified in regards the longitudinal and transverse directions, respectively.

\section{b. $\quad$ Fatigue test set-up}

Tests carried out in regards fatigue crack growth were devised and carried out across 4-point bend specimens with the use of a servo-hydraulic Instron machine, incorporating a maximum load carrying capacity of $100 \mathrm{kN}$ (see Figure 7). The calculation of the applied load was carried out through consideration to the SFC so as to ensure plasticity at the notch tip was avoided. In order to examine the influence of different stress levels on the fatigue crack growth behaviour of the material, two maximum load cases of $70 \mathrm{kN}$ and $60 \mathrm{kN}$. Across all tests, a frequency of $3 \mathrm{~Hz}$ and a load R-radio of 0.1 was applied. An overview of the loading conditions applied across all of the tests can be seen detailed in the table below. 


\section{c. Inspection and Monitoring of Crack}

The approach of Alternating Current Potential Difference (ACPD) was carried out in order to monitor and accordingly measure the depth of crack throughout the completion of fatigue crack growth tests. ACPD is recognised as a non-destructive approach, involving the injection of a conductor into the current, which subsequently causes the outer surface to be exposed to a thin layer of current flow, commonly referred to as the skin effect. Owing to the current passing through a small region of the material, there is the generation of high surface voltage [18]. Importantly, two different connections between the instrument and specimen are necessary when applying the ACPD; these are the current output or field connection and the voltage input. The latter may be an individual probe or could stem from numerous probes in the monitoring of crack growth throughout testing [19][20]. When applying this approach, the Alternating Current (AC) is injected at one side of the crack (P1). This then flows across the surface of the specimen, before travelling up and down the crack itself, and then passing out of the crack at the other side (P2). This movement can be seen depicted in Figure 8. Further, the current travels through the skin of the specimen's thickness $(\delta)$ and further involves depth crack (d). Voltage decline is measured with the use of a probe with a fixed distance between its individual electrodes $(\Delta) .[21]$

$$
d=\frac{\Delta}{2}\left(\frac{V_{2}}{V_{1}}-1\right)
$$

Equation 1

where:

The reference voltage is represented by V1; this is measured away from the crack. The voltage measured across the sides of the crack are represented by V2. Furthermore, the depth of the crack is represented by the voltage ratio through a calibration process.

In the present project, in an effort to complete measurement and observations of the growth of crack, the voltage connections were fixed on the specimen; this was achieved with the use of spot welded pins (see Figure 9). In an effort to monitor the development and growth of the crack across the test specimens, eight sets of spot welded pins were applied. Further, a pin was adopted in an effort to eradicate common-mode voltage, as can be seen detailed in Figure 9. 


\section{d. Method to Test Fatigue Crack Growth}

There was the completion of fatigue crack growth tests on 4-point bend specimens. The temperature was $25^{\circ} \mathrm{C}$. The samples were subjected to the sinusoidal wave loads, which had been adopted in the wave matrix software provided by Instron. Across the fatigue tests, a loop wave matrix was implemented in order to account for additional steps so as to secure the specimen under mean load; on the other hand, in order to ensure accurate ACPD measurements, the crack mouth was open (see Figure 10). There was the design and implementation of a loop sequence in the wave matrix so as to allow for the application of fatigue loading to the test specimens. All of the loops underwent division across three individual stages, totalling 14.5 minutes. The three different stages can be seen broken down as follows:

Step 1: Ramping up the specimen to the minimum load (within 2 seconds).

Step 2: Applying the sinusoidal load between maximum and minimum loads.

Step 3: Holding for 26 seconds at the mean load so as to enable ACPD measurement to be carried out during the crack mouth being open.

\section{e. An Examination of Fatigue Crack Growth}

The specimen geometry reviewed in this work underwent stress intensity factor calculation in line with the framework presented by Newman \& Raju [22]. This particular framework comprises equations with the aim of measuring the stress intensity factor across semi-elliptical surface cracks, which are known to be influenced by crack depth, crack length, plate thickness, plate width and parametric angle for tension and bending loads. The framework was originally designed in line with a three-dimensional finite element examination for an elastic plate, which was exposed to tension loading or pure bending conditions.

As highlighted by the framework of Newman \& Raju [22], the stress intensity factor in the case of combined tension and bending load may be determined through the application of the following:

$$
K_{I}=\left(S_{t}+H S_{b}\right) \sqrt{\pi \frac{a}{Q}} F\left(\frac{a}{t}, \frac{a}{c}, \frac{c}{b}, \phi\right) \quad \text { Equation } 2
$$

where: 
$\mathrm{K}_{\mathrm{I}}$ is the stress intensity factor for Mode I.

The average crack extension may be applied on a per cycle basis in order to determine the fatigue crack growth rate, which may be recognised as the crack extension rate as a result of fatigue loading. In order to calculate the fatigue crack growth rate in line with ASTM E647, a 7-point incremental polynomial approach — which is notably valuable for the continuous and smooth testing - was applied [23]. Through the adoption of the incremental polynomial method, the fatigue crack growth rate was determined through the application of the following equations:

$$
a_{i}=b_{0}+b_{1}\left(\frac{N_{i}-C_{1}}{C_{2}}\right)+b_{2}\left(\frac{N_{i}-C_{1}}{C_{2}}\right)^{2}
$$

Equation 3

where

$$
\begin{array}{ll}
-1 \leq\left(\frac{N_{i}-C_{1}}{C_{2}}\right) \leq+1 & \text { Equation } 4 \\
\left(\frac{d a}{d N}\right)_{a i}=\left(b_{1}\right) /\left(C_{2}\right)+2 b_{2}\left(N_{i}-C_{1}\right) / C_{2}^{2} & \text { Equation 5 }
\end{array}
$$

where:

$\mathrm{b}_{0}, \mathrm{~b}_{1}$, and $\mathrm{b}_{2}$ are the regression parameters that may be established through the adoption of the least square method.

\section{Experimental Findings Collated from Tests on Fatigue Crack Growth}

\section{Crack Length Measurements}

The tests carried out in regards fatigue were completed on 4-point bend specimens. In total, 7 specimens were tested in an effort to examine the influence of partial peening on the growth behaviours demonstrated in terms of fatigue crack when exposed to bending loads. Importantly, the monitoring of fatigue crack growth was carried out in relation to the specimens' width and thickness through the use of ACPD. As has been discussed previously and is detailed in Table 1, the first four specimens, notably referred to as A10-1, A20-1, A30-1 and A60-1, underwent testing with exposure to a $70 \mathrm{kN}$ maximum load and load ratio of $\mathrm{R}=0.1$; the remaining three 
specimens, referred to as A10-2, A20-2 and A30-2, underwent testing with exposure to a $60 \mathrm{kN}$ maximum load and $\mathrm{R}=0.1$. The measurements for the fatigue crack length, as derived from the ACPD measurements, were plotted in relation to fatigue cycles for the A20-1 specimen, as detailed in Figure 11; this provides an example. Comparable measurements were implemented across all other test specimens. The Figure details data sets for $10-80 \mathrm{~mm}$ distance from the specimen's outer edge — notably provided as a point of reference-along the specimen width. When drawing a comparison between the growth of the crack at $20 \mathrm{~mm}$ and $80 \mathrm{~mm}$ distance from the outer edge, it may be recognised that comparable patterns can be identified as a result of symmetrical peening in relation to the symmetry line offered by the specimen. In this vein, the figure highlights the initiation of the fatigue crack at the specimen's mid-width - notably $50 \mathrm{~mm}$ from the outer edge and across the symmetry line of the specimen-where the starter crack had been incorporated onto the specimen with the machine. As can also be identified in the figure as well as when reviewing the results garnered from other tests carried out in line with exposure to $70 \mathrm{kN}$ maximum load, crack retardation as a result of cavitation shotless peening was not evident in the growth behaviour of the specimen's fatigue crack, which was exposed to $70 \mathrm{kN}$ maximum load, with smooth crack growth patterns undergoing measurement across the whole period of fatigue tests. Nonetheless, across the three tests carried out lastly, with exposure of $60 \mathrm{kN}$ maximum load, there is evident crack retardation, as shown in the crack growth data, as shown in Figure 12 as an example for A20-2. 


\section{Shape Evolution Results of Crack}

The evolution of the fatigue crack shape underwent monitoring throughout the testing of fatigue with the application of ACPD probes aligned with the specimens' width. The length of the fatigue crack, as provided through each probe's readings, are detailed against the probe distance from the outer edge, as shown in Figure 13 (a - d) for for A10-1, A20-1, A30-1 and A60-1, respectively. Across all of the specimens that underwent testing, the measurements were repeated at various cycle numbers in an effort to garner insight into the shape evolution of the crack across all fatigue tests. When drawing a comparison between figures $13(\mathrm{a}-\mathrm{d})$, it may be recognised that, for specific loading conditions (maximum load of $70 \mathrm{kN}$ with $\mathrm{R}=0.1$ ), partial surface peening extent has a notable impact on the shape evolution of the crack across different specimens. It may also be recognised through reviewing the figures that the crack with the greatest depth in all specimens underwent measurement at the samples' mid-width, as expected, with shorter cracks identified in those areas that had been peened where there was the presence of compressive residual stresses. Contrasting figures 16-18, it can also be recognised that the growth of the fatigue crack at A10-1 specimen's mid-width was quicker when compared with both A30-1 and A20-1. This is recognised as being as a result of higher tensile residual stresses in the specimen's unpeened regions. Importantly, the diagrams validate the view that the evolution of the fatigue crack shape and rate in the bend specimens is controlled as a result of the partial surface peening.

Crack aspect ratio evolution can be seen displayed in Figure 14 for those specimens that underwent testing under pure bending in the present work. In this paper, the crack aspect ratio may be defined as the fatigue crack depth ' $a$ ' to fatigue crack length 'c' ratio; this has been plotted in alignment with the fatigue crack depth ' $a$ ' to specimen depth ' $t$ ' ratio, as shown in Figure 14. Notably, it has been established previously in published work that, when exposed to pure bending loads, there is a tendency for fatigue crack to grow to reach an optimum ratio, irrespective of the shape of the initial crack [2]. It has also been recognised and detailed in past works that the evolution of the crack shape relies on loading modes and material anisotropy; however, it remains independent of the stress magnitude applied [2]. As also depicted in Figure 14 , as a result of partial cavitation shotless peening, which is notably responsible for resulting in material anisotropy, there has been a change to the crack aspect ratio, which displays deviation from the more desirable pattern of a straight line. 


\section{Results for the Rate of Fatigue Crack Growth}

Across all tests, the data pertaining to fatigue crack growth underwent examination with the application of the equations and processes highlighted in Section 2. The rates of fatigue crack growth, $d a / d N$, underwent calculation with the use of a 7-point polynomial approach for all tests, and were found to correlate with the stress intensity factor range, $\Delta K$. There is a need to recognise that, for the examination of fatigue crack growth, the crack lengths with the greatest depths underwent measurement at the specimens' mid-width point when implemented in calculations. The rates of the fatigue crack growth, as derived from the tests on the numerous specimens, namely A10-1, A20-1, A30-1, A60-1, A10-2, A20-2 and A30-2, can be seen in Figure $15(\mathrm{a}-\mathrm{g})$. Across all of these figures, the decreased rate of fatigue crack growth at the entrance to the peened area is enlarged and therefore presented at a larger scale for the purpose of clarity. In the case of the first test for specimen A10-2, as shown in Figure 15 (a), it is clear by the plotted results that the growth of the fatigue crack against $\Delta K$ highlights a linear pattern in $\log -\log$ scale, in addition to a decline in the growth rate of the fatigue crack throughout the preliminary phases of the test; this is aligned with the time at which the tip of the crack reached the partially peened region. For the results of the specimens A20-1 and A30-1, it may be recognised that there is a linear pattern between the growth rate of the fatigue crack and $\Delta K$ in $\log -\log$ scale, notably comparable to A10-1, with a comparable decline in the growth rate of the fatigue crack upon the entering of the tip of the crack into the peened area. Figure 15 (d) provides that, across the inherent experimental scatter, there is no noticeable decline in the growth rates of fatigue crack in unpeened specimens; this was predicted. Moreover, as shown in figures 18 (e to $\mathrm{g}$ ), a clearer decline in the growth rate of fatigue crack is recognisable in those specimens exposed to a lower load level during testing. This is viewed as an observation consistent with those exposed to a maximum load.

\section{Fractography}

The validation of the ACPD measurements was achieved through drawing a contrast between the measurement of the final crack length following the conclusion of the testing with that measured on the fracture surface following the breaking open of the specimen under testing. The ACPD measurement percentage error at the greatest point of depth was identified as being relatively minor at $\pm 3 \%$. This further validates that ACPD is a valuable and accurate approach to the prediction of crack length across sample widths. Following testing, the specimens were 
subjected to immersion in liquid nitrogen for a period of 30 minutes, with the specimens subsequently broken up on an Instron machine. All of the specimens demonstrating fatigue crack growth underwent examination at the fracture surface following being broken open; those for the A10-1 and A30-1 specimens can be seen detailed in figures $16-17$, respectively. The images present a clear view that distinctive areas may be recognised on the broken open specimens' fracture surface, as established and highlighted in figures 16-17. Primarily, the point at which the fatigue crack is instigated following machining, incorporating the common semi-elliptical fatigue crack evolution shape, can be identified on the surface of the fracture. It may be clearly recognised that a transition area spanning from fatigue through to fast fracture is apparent towards the conclusion of tests where the stress intensity factor gets closer to its critical value in the region of increasing fatigue crack growth. Lastly, as a result of the breaking up of the specimen, the fast fracture region may be identified on the specimens' fracture surface. As further recognised in fractography works, high-resolution images do not allow for the identification of slower fatigue crack growth behaviour across peened areas; however, such areas have been clearly identified in figures $16-17$.

\section{Discussion}

The results garnered from the tests carried out in this work in regards the growth of fatigue crack are presented and a comparison drawn in Figure 18. The figure provides a clear overview to show that partial surface cavitation shotless peening has a significant and notable impact on the growth behaviour demonstrated by a material in regards fatigue crack. The findings demonstrated in the case of Specimen A60-1 emphasise that the growth rate of fatigue crack provides a linear increase alongside an increase in stress intensity factor when there is the plotting of data across the $\log -\log$ axis. Such a demonstration is referred to as the Paris law, and is commonly recognised across all tests carried out in relation to fatigue crack growth [24]. It is also apparent when reviewing Figure 18 that growth rate reduction concerning fatigue crack has been identified across all specimens that have been exposed to partial peening, with retardation at a lower, intermediate and higher $\Delta K$ value demonstrated in the cases of $\mathrm{A} 10, \mathrm{~A} 20$ and $\mathrm{A} 30$, respectively, when exposed to load levels of both $60 \mathrm{kN}$ and $70 \mathrm{kN}$. This emphasises that the stress intensity factor range at which there is the occurrence of fatigue crack retardation increases in line with an increase of the area of the unpeened region on the surface of the analysed specimens. A contrast pertaining to the test results garnered from specimens A10-1, 
A20-1 and A30-1 and A60-1, as detailed in Figure 18, emphasise that the lowest and greatest growth trends of fatigue crack can be seen in A60-1 and A20-1, respectively, with the test data from the samples of A10-1 and A30-1 recognised as close to one another. It may also be recognised through observing this figure that, for a specific value of $\Delta K$, in the A20-1 partially peened specimen, the growth rate of fatigue crack is approximately 1.6 times quicker than a sample that has not been peened. As can be seen when reviewing Section 2, rates of growth amongst cracks in partially peened specimens are recognised as quicker when there is tensile residual stresses created in the unpeened region of the specimen owing to the peening process. The results gathered following a contrast between the A10-2, A20-2, A30-2 specimens, as detailed in Figure 18, emphasise that the growth trends in fatigue cracks were greatest in the case of A30-2 and lowest in A10-2, whilst that of A20-2 was seen to be in between. It may also be recognised through reviewing this figure that, for a specific $\Delta K$ value, the growth rate of fatigue cracks in the specimen of A30-2 — notably partially peened — is approximately 1.7 times quicker than the sample A10-2. The test results undergoing a comparison provided results, which show that, for samples A10-1, A20-1 and A30-1, despite the fact that the growth rate of fatigue crack was lesser owing to partial surface cavitation shotless peening, it remains that, as a result of higher load tests, greater fatigue crack growth patterns can be recognised $(70 \mathrm{kN}$ maximum load) when contrasted alongside those tested at a lower load (i.e. $60 \mathrm{kN}$ maximum load). Such a finding validates the view that, despite the fact that partial surface cavitation shotless peening is seen to have an effect on the growth behaviour of the fatigue crack in a material, to the same degree of partial peening, the growth rate of the fatigue crack in the partially peened sample increases in line with increased applied load. As shown through the findings, it may be recognised that the partial cavitation shotless peening influence is positive for FCGR, with the FCGR recognised as showing a decline at the entrance of the partial shotless peening alongside a decrease in the general trend of FCG alongside an increase in the partial peening area when exposed to pure bend load. This is owing to the front of the fatigue crack being influenced as a result of the compressive residual stress caused by the peening area more so than that of the tensile residual stress, which subsequently results in FCG decreases and fatigue life improvement, as shown in Figure 19. 


\section{Conclusions}

Partial surface peening on the growth behaviour of fatigue crack in the case of a high-strength steel material has been examined in terms of the effects of such when exposed to bending loads. The research was carried out through the completion of fatigue tests across 4-point bend specimen geometry. The work considered growth rates of fatigue crack and the evolution of fatigue crack shape. Notably, there was the application of ACPD approaches in an effort to complete fatigue crack depth measurement, in addition to the width of the samples. A total of seven specimens with varying degrees of partial peening regions underwent testing under two different load levels, with a load ratio of $\mathrm{R}=0.1$ in all tests. Based on limited testing preliminary qualitative, a number of conclusions have been arrived at as a result:

1. The partial surface cavitation shotless peening presented a number of positive compressive residual stresses of up to $550 \mathrm{MPa}$ with a penetration depth of approximately $0.5 \mathrm{~mm}$ under the outer surface of the test specimens.

2. There was the generation of tensile residual stresses in the unpeened areas of the partially peened specimens as a result of the force equilibrium.

3. The evolution of fatigue crack shape was affected by the cavitation shotless peening as a result of compressive residual stress.

4. Cavitation shotless peening provides an outcome of good surface finish when contrasted alongside shot peening.

5. Fatigue crack growth rates are seen to decrease when the tip of the fatigue crack enters the cavitation shotless peened area in the case of those specimens that have been partially peened.

6. The range of stress intensity factor, at which the fatigue crack retardation was seen in partially peened specimens, enlarged by enlarging the area of the unpeened region (i.e. reducing the area of the peened region).

7. A greater pattern of fatigue crack growth was witnessed across partially peened samples when exposed to greater load levels.

8. Partial peening has a more significant effect on fatigue crack retardation when tests are carried out at a lower load.

9. For those tests carried out under exposure to lower loads, the pattern of fatigue crack growth was seen to be at its lowest in the specimen with the greatest peened area. 


\section{References}

[1] K. M. M. M. J. Senatore and R. Chieragatti, "The effect of roughness and residual stresses on fatigue life time of an alloy of titanium," Int J AdvManuf Technol, pp. 557$563,2015$.

[2] F. P. Brennan, S. S. Ngiam, and C. W. Lee, "An experimental and analytical study of fatigue crack shape control by cold working," Eng. Fract. Mech., vol. 75, no. 3-4, pp. 355-363, Feb. 2007.

[3] F. P. Brennan, S. S. Ngiam, and T. Place, "Fatigue Crack Shape Control under Bending by Cold Working," in In: Proc Int Conf Fat Crack Paths, 2006.

[4] S. S. Ngiam and F. P. Brennan, "Crack Shape Control using Cold Rolling," Proc. Fatigue Crack Paths (FCP 2003), 2003.

[5] D. Lados and D. Apelian, "The effect of residual stress on the fatigue crack growth behavior of Al-Si-Mg cast alloys-Mechanisms and corrective mathematical models," Metall. Mater. Trans. A, vol. 37, no. 1, pp. 133-145, 2006.

[6] L. Doremus, J. Cormier, P. Villechaise, G. Henaff, Y. Nadot, and S. Pierret, "Influence of residual stresses on the fatigue crack growth from surface anomalies in a nickelbased superalloy," Mater. Sci. Eng. A, vol. 644, no. August 2015, pp. 234-246, 2015.

[7] H. Soyama, D. O. Macodiyo, and S. Mall, "Compressive residual stress into titanium alloy using cavitation shotless peening method," Tribol. Lett., vol. 17, no. 3, pp. 501$504,2004$.

[8] D. Odhiambo and H. Soyama, "Cavitation shotless peening for improvement of fatigue strength of carbonized steel," Int. J. Fatigue, vol. 25, no. 9-11, pp. 1217-1222, 2003.

[9] H. Soyama, Y. Sekine, and Y. Oyama, "Improvement of the Fatigue Strength of Stainless Steel SUS316L by a Cavitating Jet with an Associated Water Jet in Water," ISIJ Int., vol. 48, no. 11, pp. 1577-1581, 2008.

[10] H. Soyama, K. Saito, and M. Saka, "Improvement of fatigue strength of aluminum alloy by cavitation shotless peening," J. Eng. Mater. Technol. Asme, vol. 124, no. 2 , pp. 135-139, 2002.

[11] H. Soyama, M. Shimizu, Y. Hattori, and Y. Nagasawa, "Improving the fatigue strength 
of the elements of a steel belt for CVT by cavitation shotless peening," J. Mater. Sci., vol. 43 , no. 14 , pp. 5028-5030, 2008.

[12] H. Soyama and N. Yamada, "Relieving micro-strain by introducing macro-strain in a polycrystalline metal surface by cavitation shotless peening," Mater. Lett., vol. 62, no. 20, pp. 3564-3566, 2008.

[13] A. Kai and H. Soyama, "Visualization of the plastic deformation area beneath the surface of carbon steel induced by cavitation impact," Scr. Mater., vol. 59, no. 3, pp. 272-275, 2008.

[14] A. Al Turaihi and A. M. F. Brennan, "The influence of partial surface shot peening on fatigue crack growth behaviour of a high - strength ferritic steel," Fatigue Fract. Eng. Mater. Struct., vol. 41, pp. 1-12, 2017.

[15] W. D. Pilkey and D. F. Pilkey, Peterson's Stress Concentration Factors. Hoboken, NJ, USA: John Wiley \& Sons, Inc., 2007.

[16] D. J. Wulpi, Why Fail, no. Ref 2. 2013.

[17] ASTM E 837:2008, "Standard Test Method for Determining Residual Stresses by the Hole-Drilling Strain-Gages," vol. 1, no. C, pp. 1-17, 2008.

[18] M. K. Raja, S. Mahadevan, B. P. C. Rao, S. P. Behera, T. Jayakumar, and B. Raj, "Influence of crack length on crack depth measurement by an alternating current potential drop technique,” Meas. Sci. Technol., vol. 21, no. 10, p. 105702, 2010.

[19] M. C. Lugg, “AN INTRODUCTION TO ACPD,” Technical Software Consultants Ltd., no. February, 6 Mill Square, Featherstone Road, Wolverton Mill, Milton Keynes, MK12 5RB UNITED KINGDOM, p. 1.1 (18), 2002.

[20] Matelect LTD, “The Potential Drop Technique \& Its Use In Fatigue Testing.” MATELECT APPLICATION NOTE REFERENCE : FPD04. Retrieved from www.matelect.com/files/Download/PDfatigueApp.pdf

[21] H. Saguy and D. Rittle, "Flaw detection in metal by the ACPD technique: Theory and experiments," NDT\&E Int., no. 2, pp. 3-7, 2007.

[22] J. C. Newman and I. S. Raju, “An empirical stress-intensity factor equation for the surface crack," Eng. Fract. Mech., vol. 15, no. 1-2, pp. 185-192, Jan. 1981. 
[23] R. Documents, "Standard Test Method for Measurement of Fatigue Crack Growth Rates," E647-11, vol. i, no. C, pp. 1-45, 2010.

[24] T. L. Anderson, FRACTURE MECHANICS Fundamentals and Applications, vol. ISBN:97808, no. 1. 2004.

[25] H. Soyama, "Cavitation S Peening ${ }^{\circledR}$ Cavitation S Peening ${ }^{\circledR}$ - Improvement of Fatigue Strength —," vol. 127, no. 4, pp. 1095-1101, 2005. 
Table 1: Fatigue crack growth test matrix for 4-point bend specimens

\begin{tabular}{|c|c|c|c|}
\hline Specimen ID & $\begin{array}{c}\text { Extent of the unpeened } \\
\text { area, A }\end{array}$ & $\begin{array}{l}\text { Number of } \\
\text { specimens }\end{array}$ & Operation load \\
\hline A10-1 & $10 \mathrm{~mm}$ & 1 & \multirow{4}{*}{$\begin{array}{l}\text { Max. load }=70 \mathrm{KN} \\
\text { Min load }=7 \mathrm{KN} \\
\text { Load ratio }=0.1 \\
\text { Loop wave matrix }\end{array}$} \\
\hline A20-1 & $20 \mathrm{~mm}$ & 1 & \\
\hline A30-1 & $30 \mathrm{~mm}$ & 1 & \\
\hline A60-1 & Without peening & 1 & \\
\hline A10-2 & $10 \mathrm{~mm}$ & 1 & \multirow{3}{*}{$\begin{array}{l}\text { Max. load }=60 \mathrm{KN} \\
\text { Min load }=6 \mathrm{KN} \\
\text { Load ratio }=0.1 \\
\text { Loop wave matrix }\end{array}$} \\
\hline A20-2 & $20 \mathrm{~mm}$ & 1 & \\
\hline A30-2 & $30 \mathrm{~mm}$ & 1 & \\
\hline
\end{tabular}




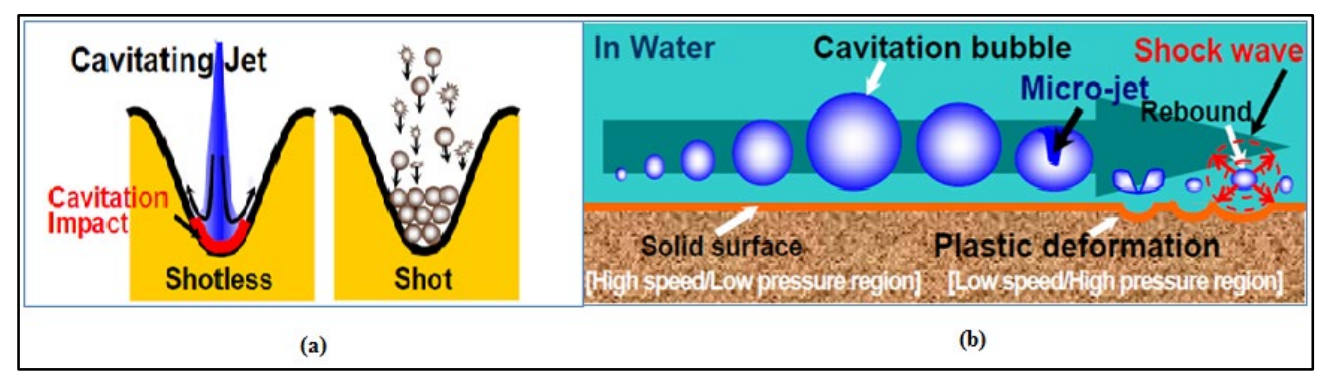

Figure 1: Schematic diagram of cavitation bubble [25]

Figure 2: Surface finish of cavitation shotless peening and shot peening 


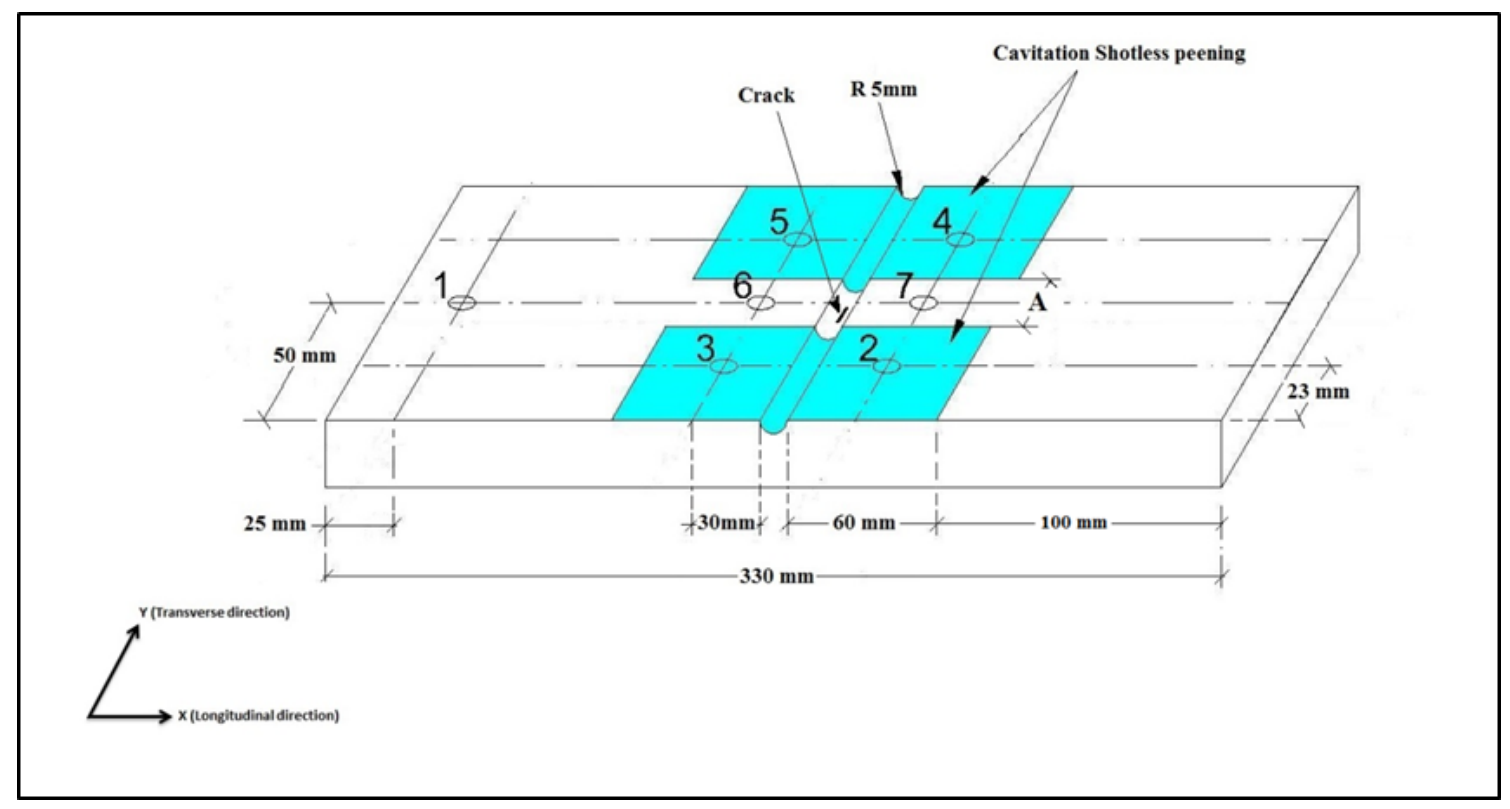

Figure 3: A schematic diagram, highlighting location of residual stress measurements

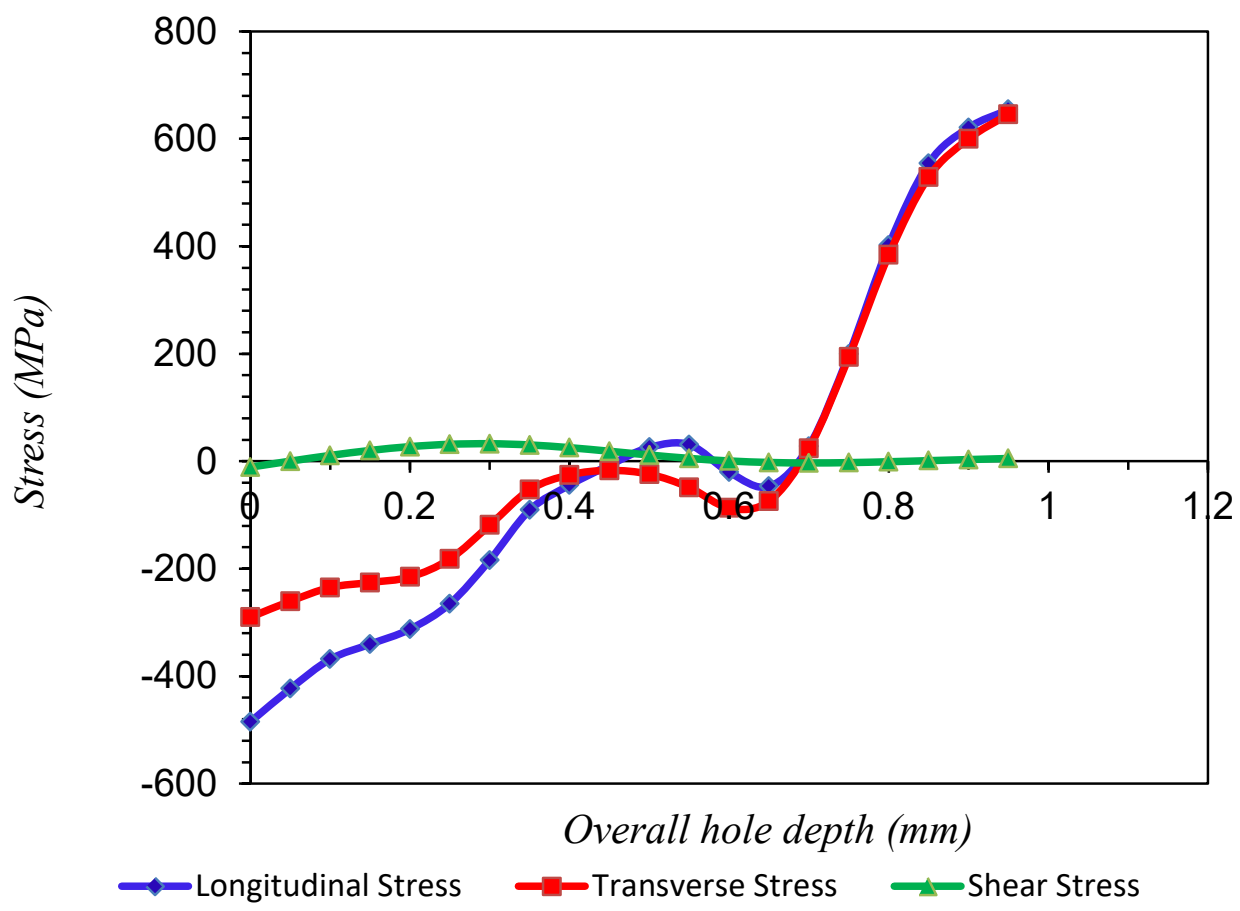

Figure 4: A20 specimen's peened area's identified residual stresses distribution 


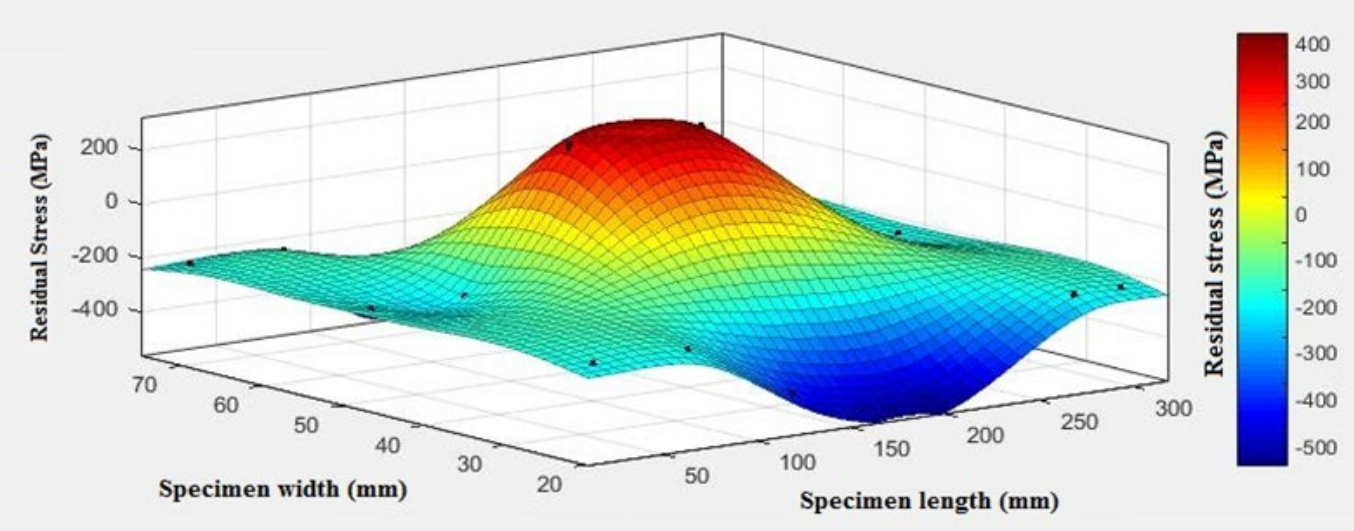

Figure 5: A20 specimen's residual stresses distribution in a longitudinal direction

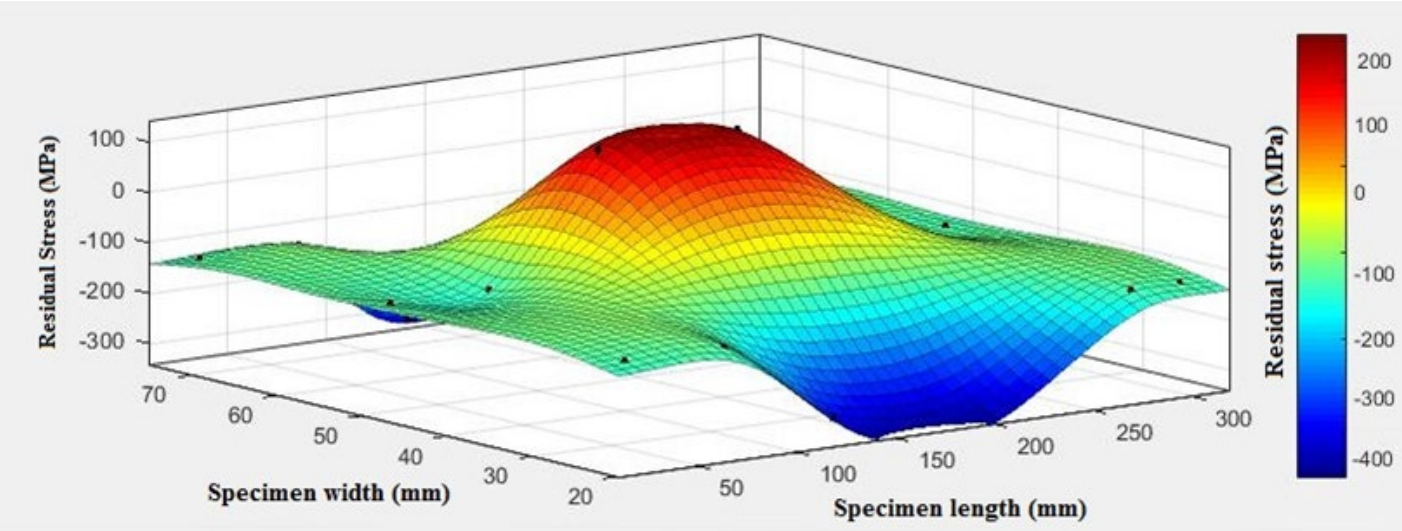

Figure 6: A20 specimen's distribution of residual stresses in a transverse direction 


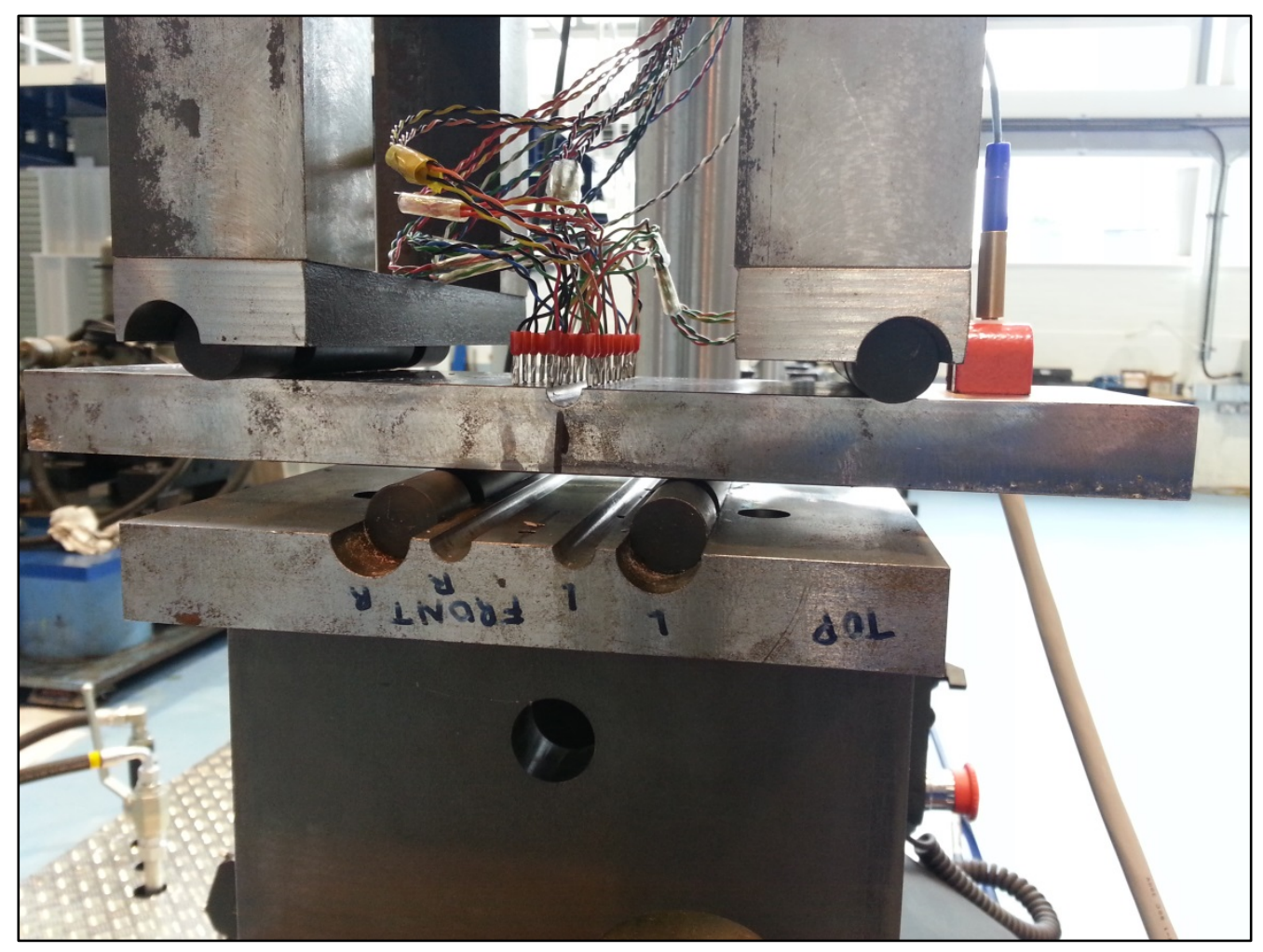

Figure 7: 4-point bend fatigue test experimental set-up

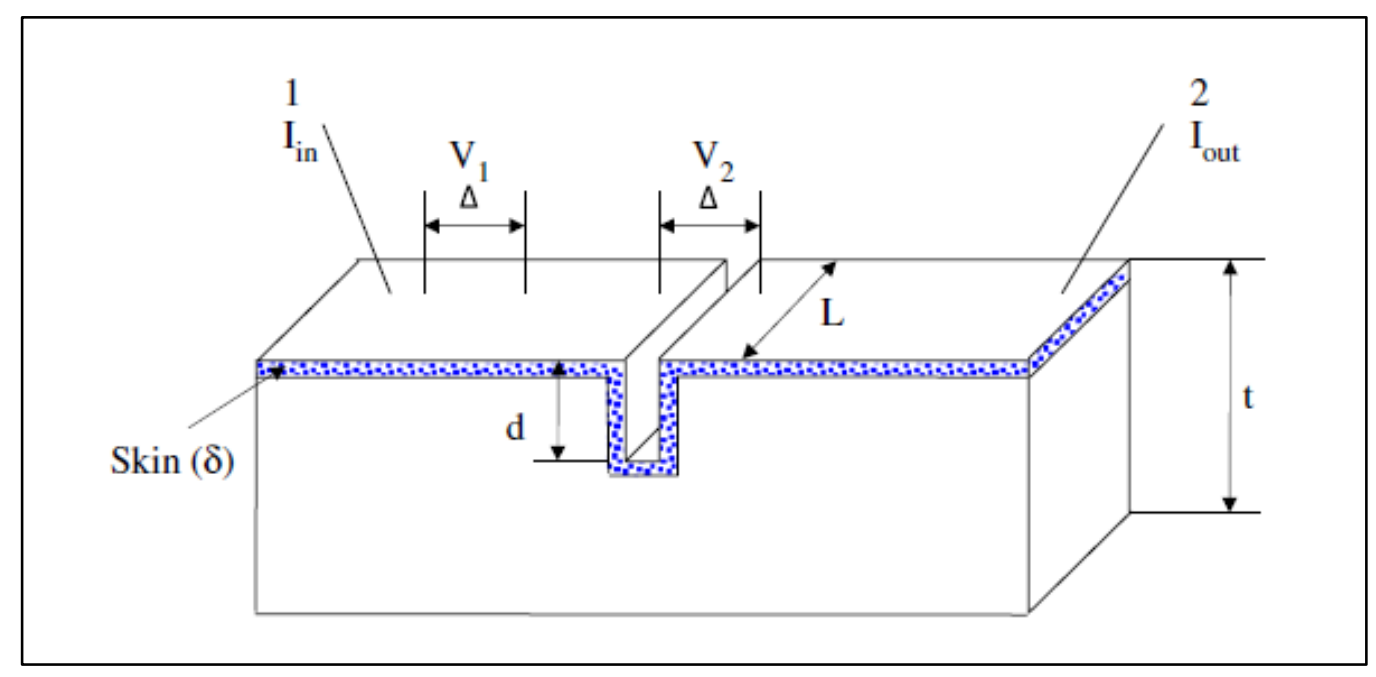

Figure 8 : A schematic overview of the ACPD approach to surface crack [21] 


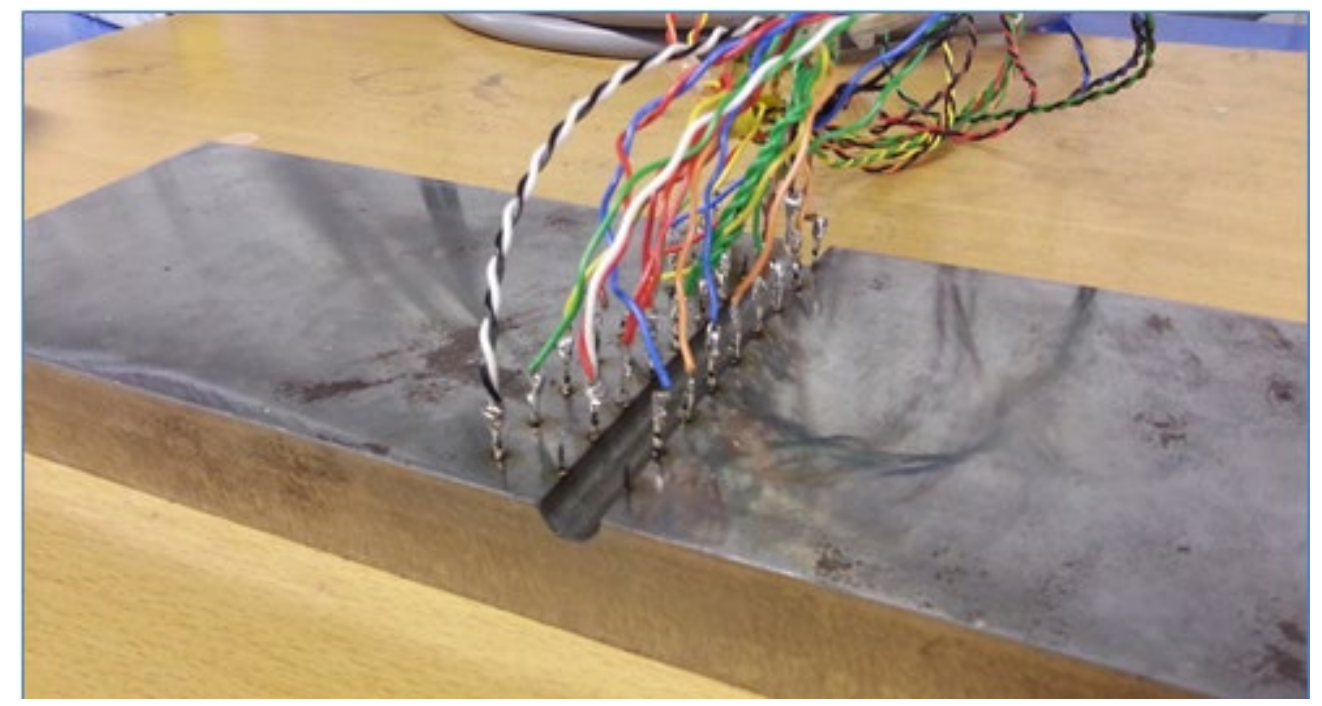

Figure 9: ACPD wires connected to spot welded pins on the specimen

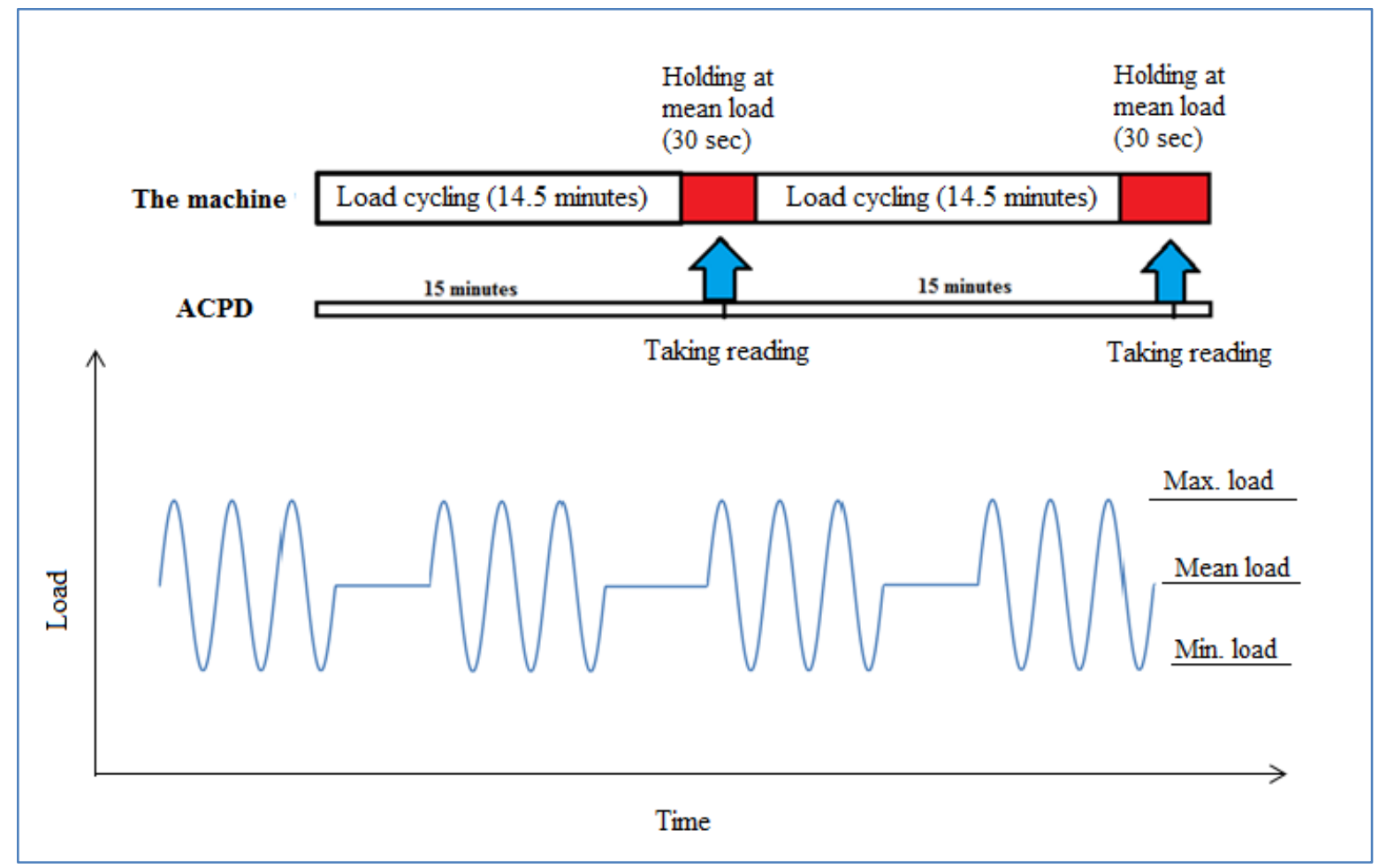

Figure 10: Loop wave matrix: a schematic overview 


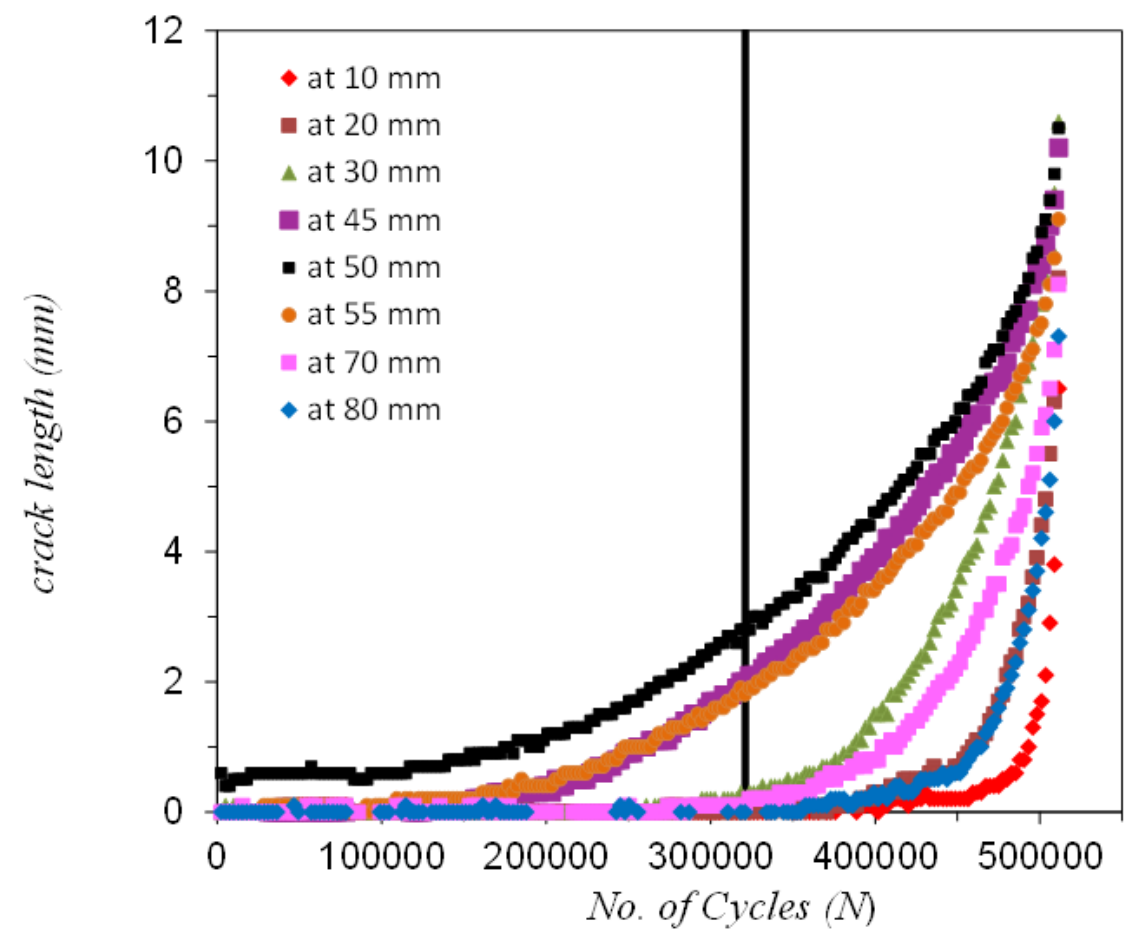

Figure 11: Fatigue crack growth data versus number of cycles for the A20-1 specimen

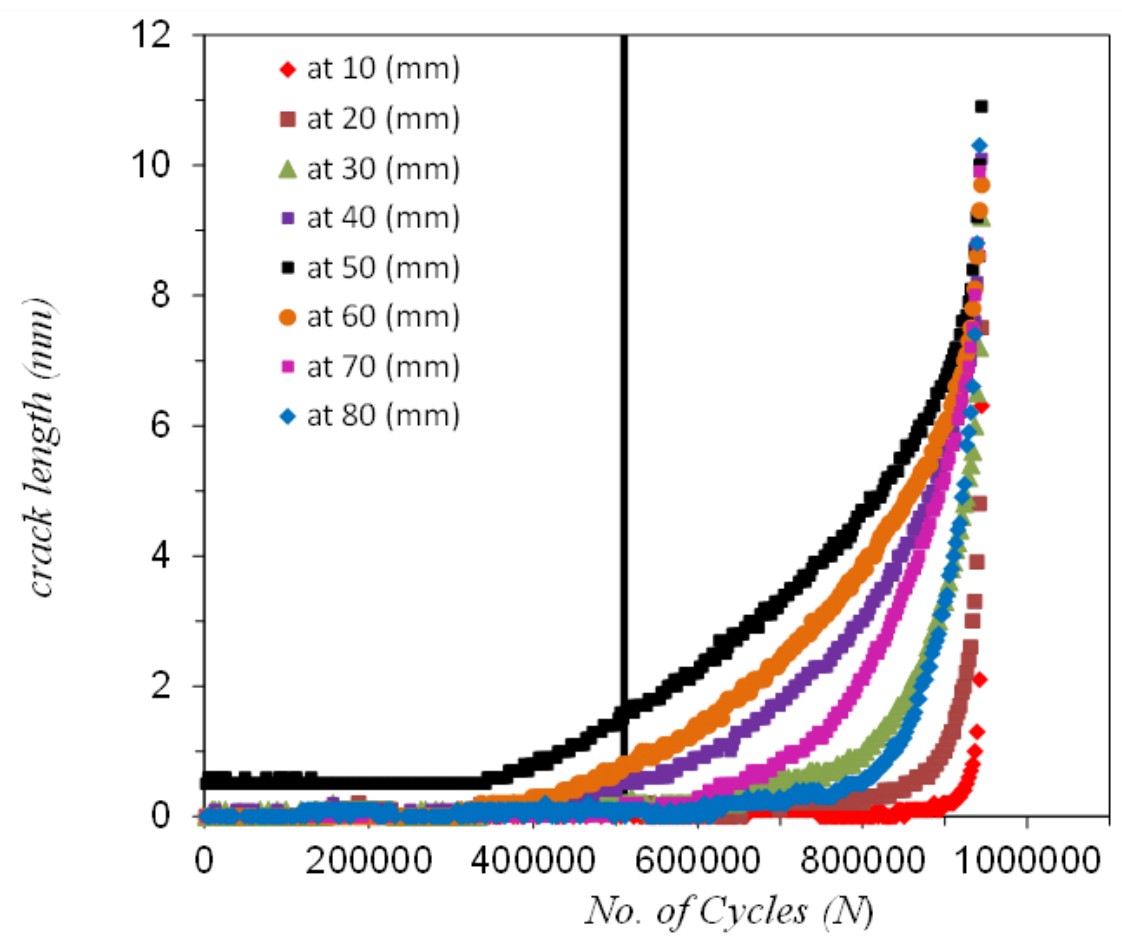

Figure 12: Fatigue crack growth data versus number of cycles for the A20-2 specimen 


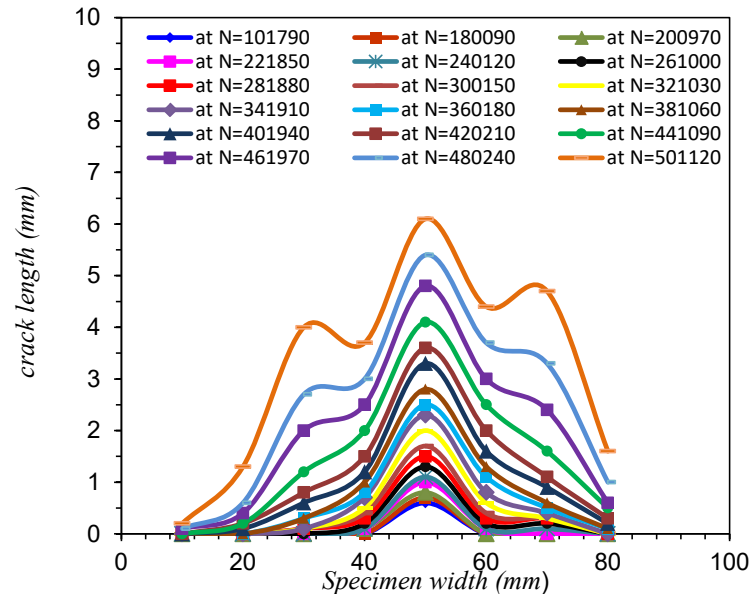

(a)

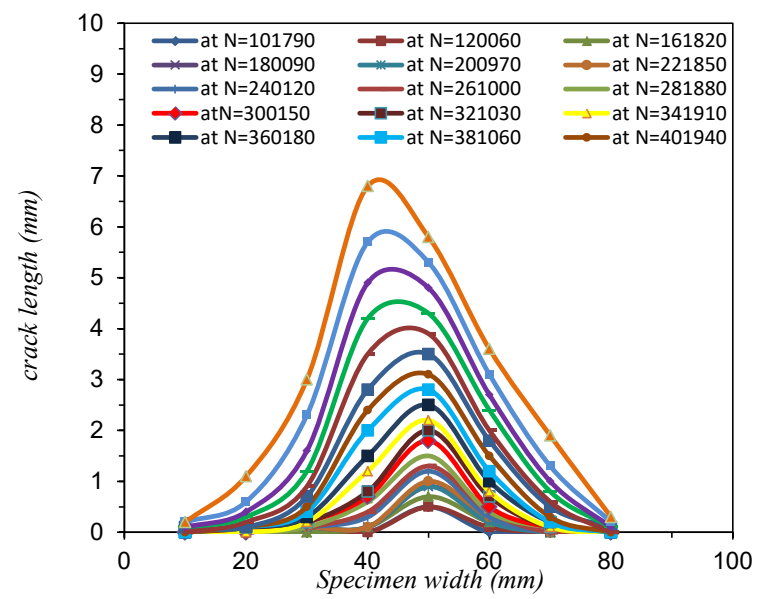

(c)

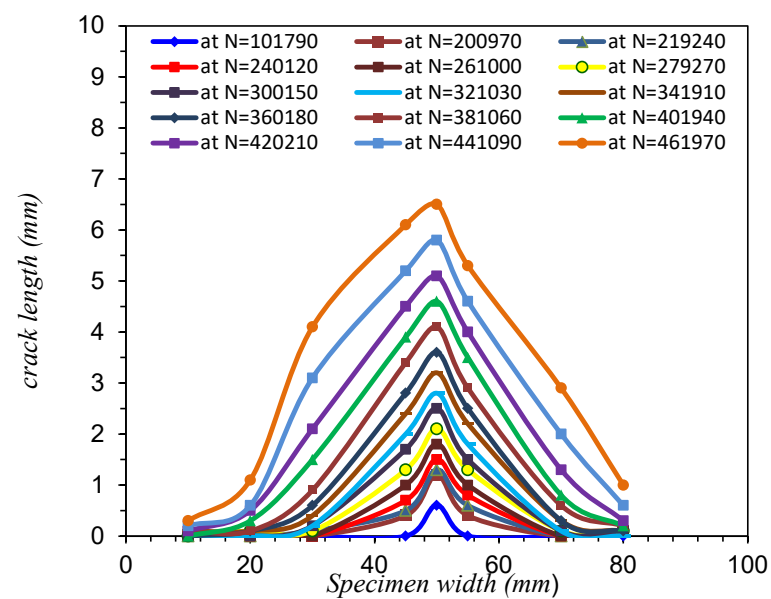

(b)

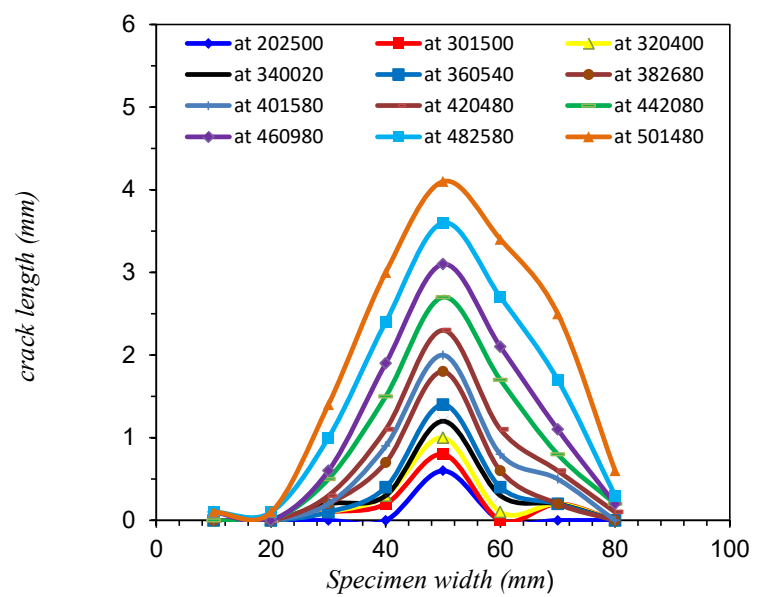

(d)

Figure 13: Evolution of crack shape: (a) for A10-1 specimen (b) for A20-1 specimen (c) for A30-1 specimen (d) for A60-1 specimen 


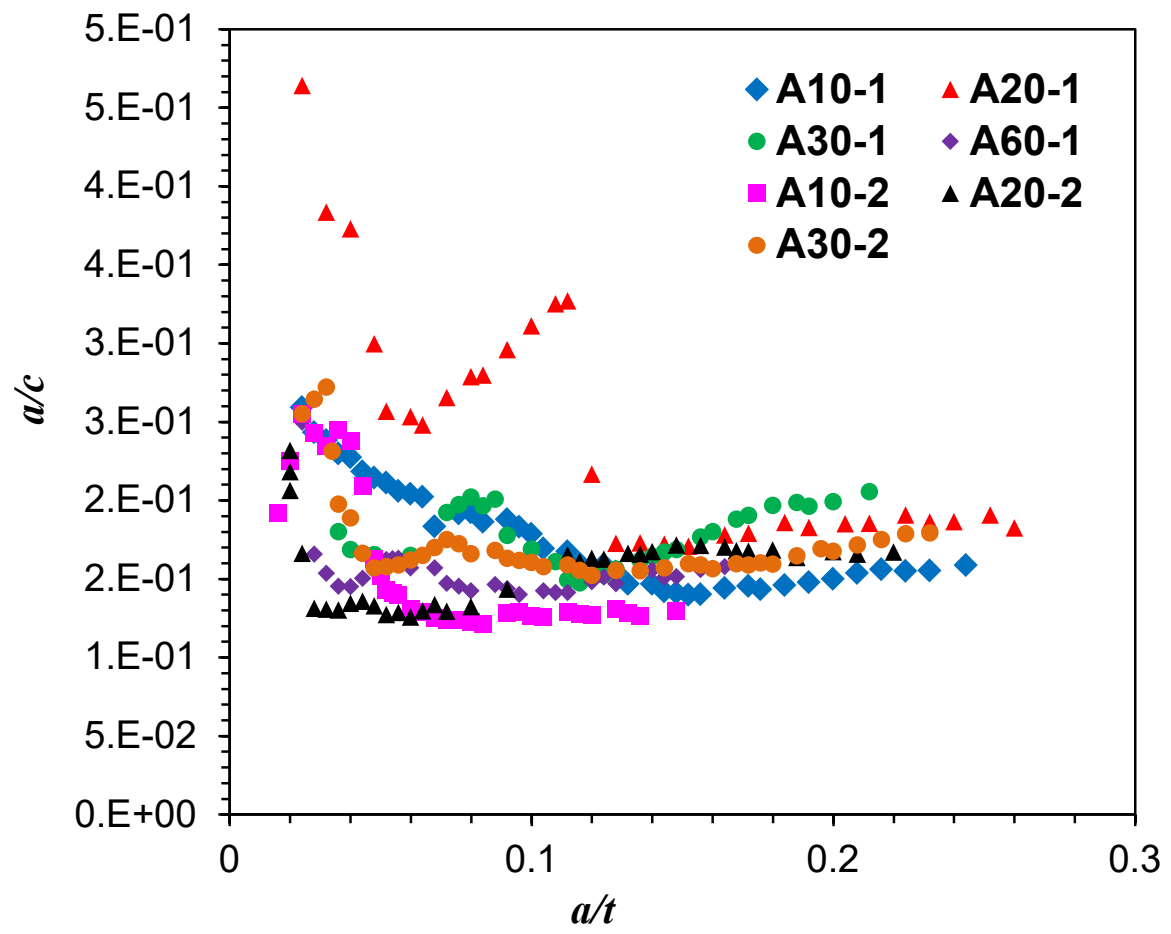

Figure 14: Aspect ratio of the evolution of fatigue crack shape across test specimens 


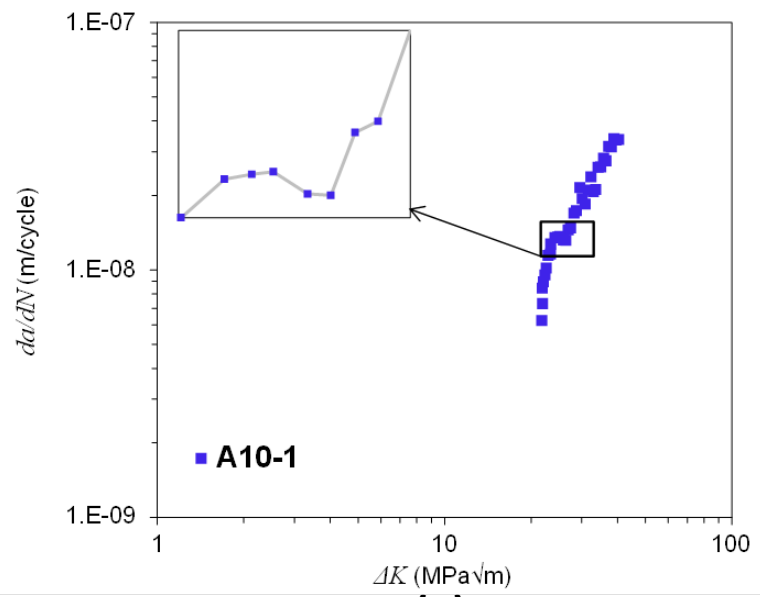

(a)

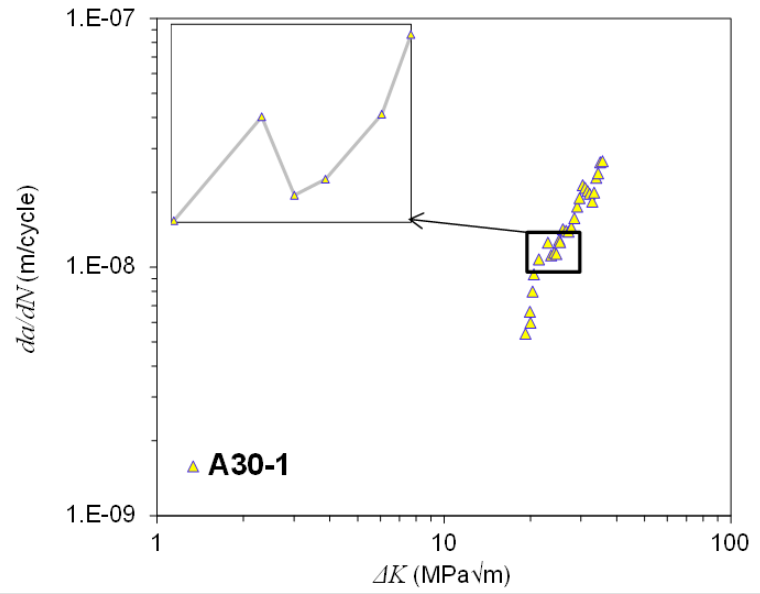

(c)

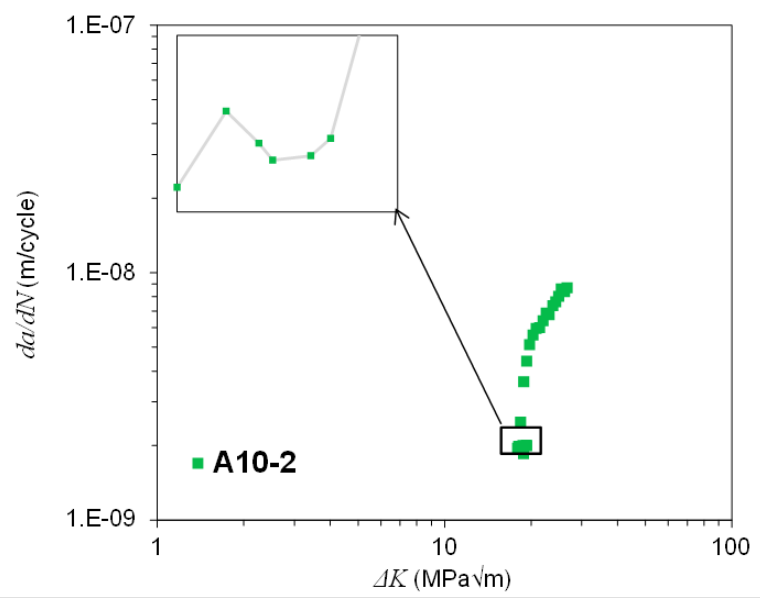

(e)

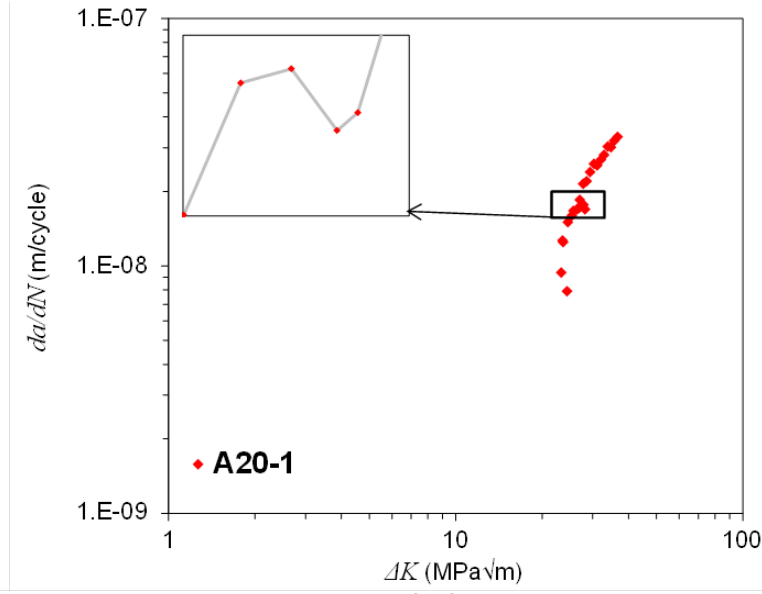

(b)

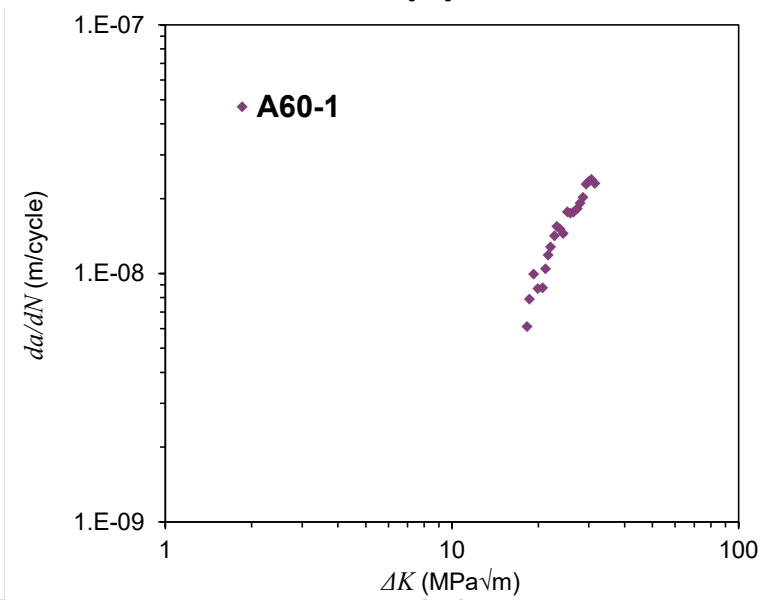

(d)

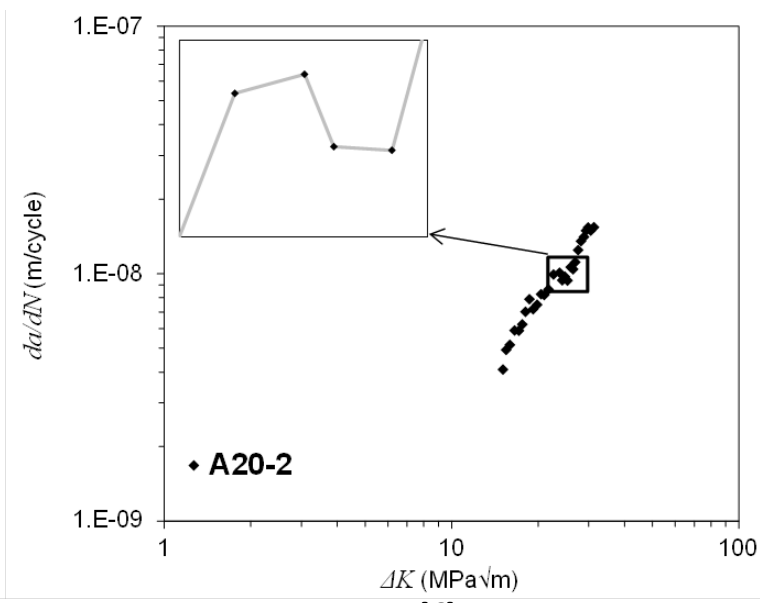

(f) 


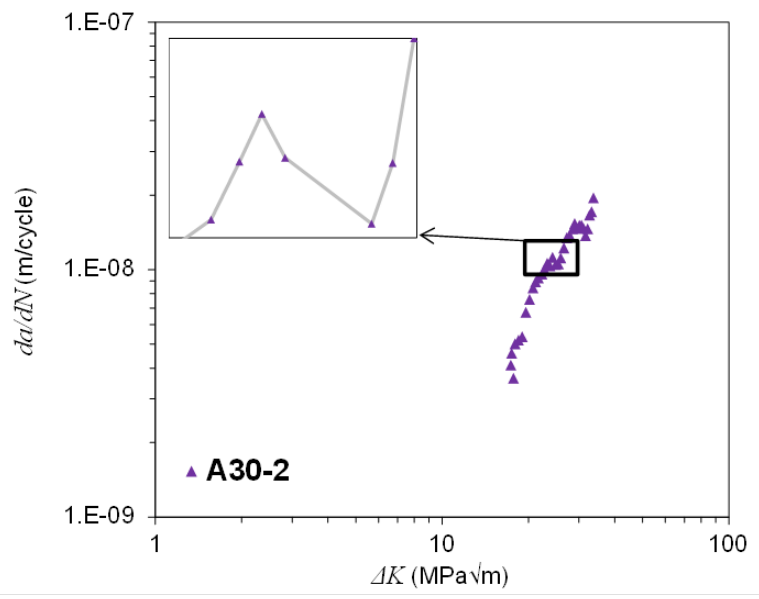

(g)

Figure 15: Fatigue crack growth results ( a) for A10-1 specimen, (b) for A20-1 specimen, (c) for A30-1 specimen (d) for A60-1 specimen, (e) for A10-2 specimen, (f) for A20-2 specimen, (g) for A30-2 specimen

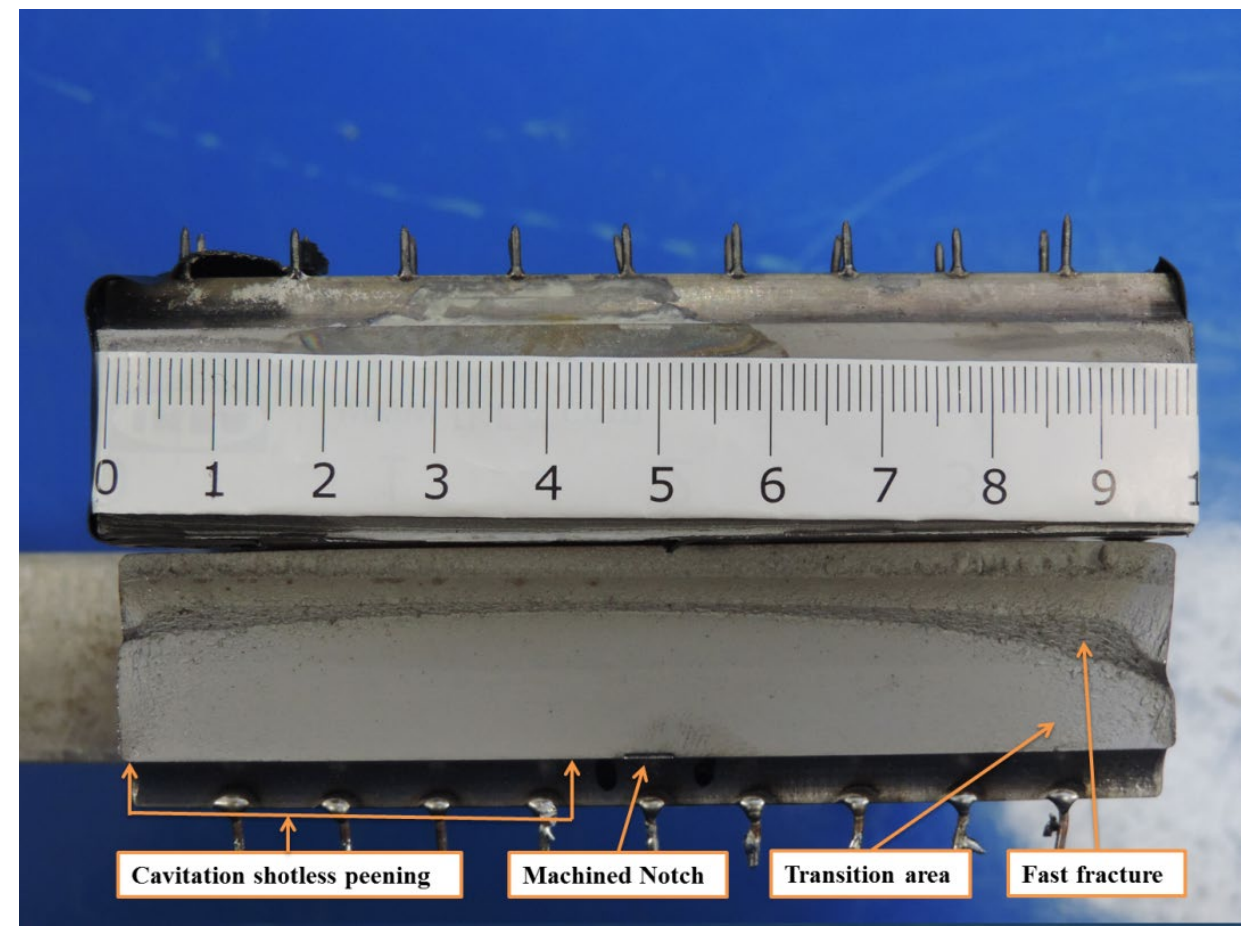

Figure 16: Fracture surface for A10-1 specimen 


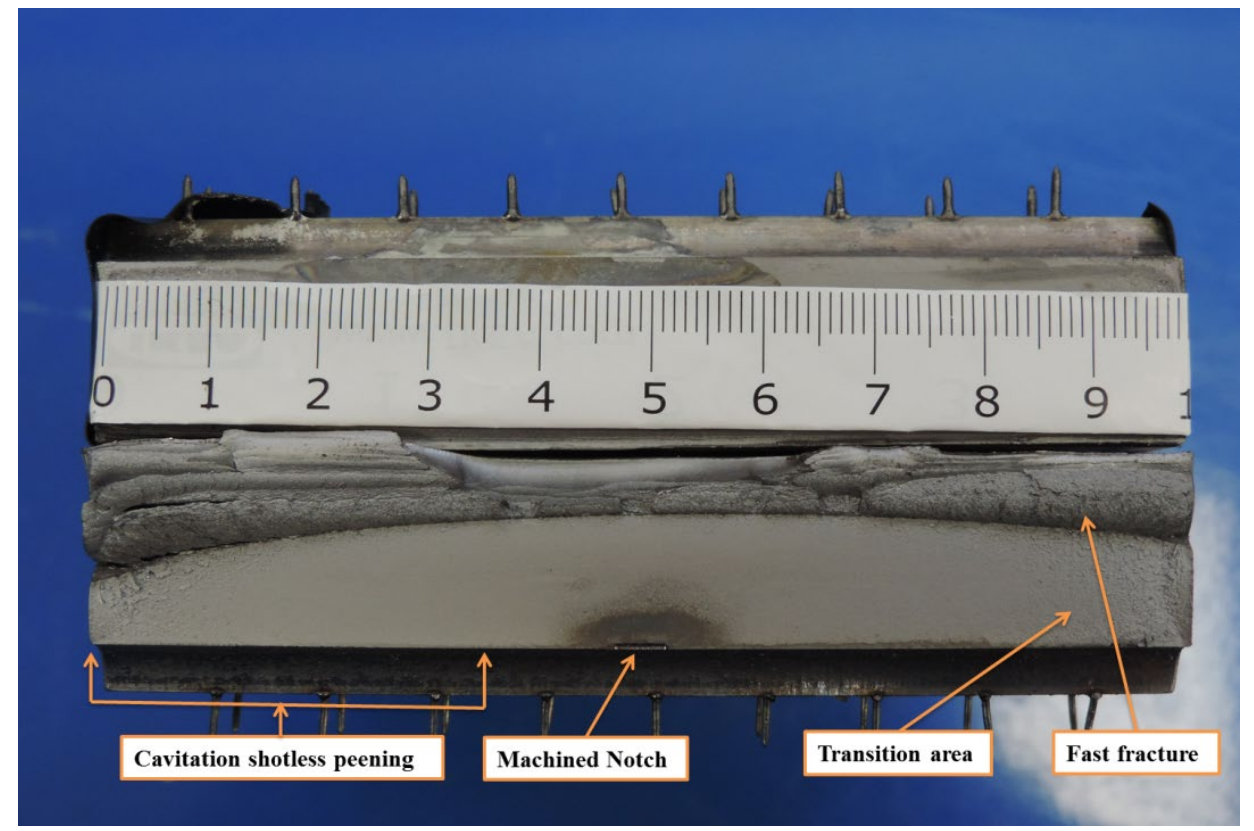

Figure 17: A30-1 specimen fracture surface

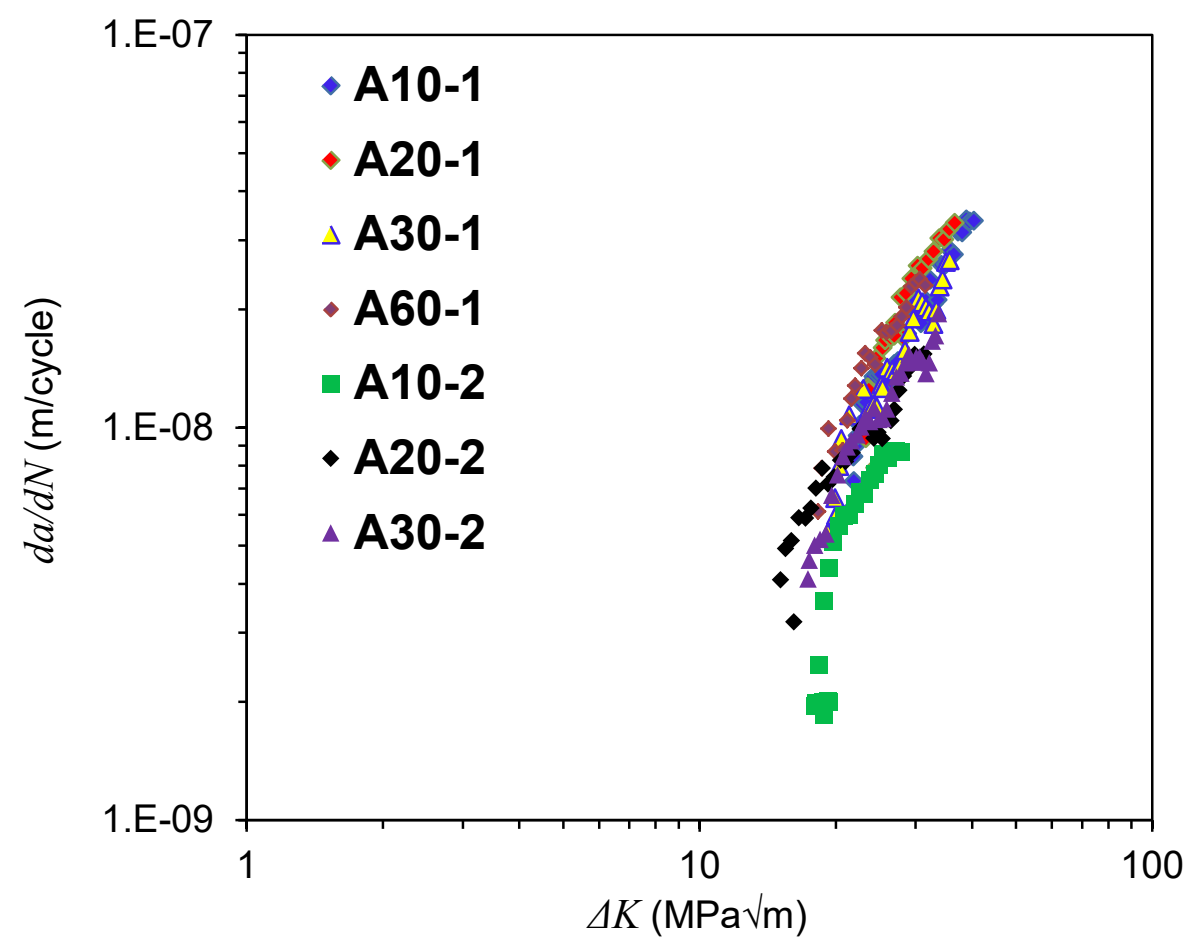

Figure 18: Growth patterns in fatigue crack growth across varying specimens: a comparison 


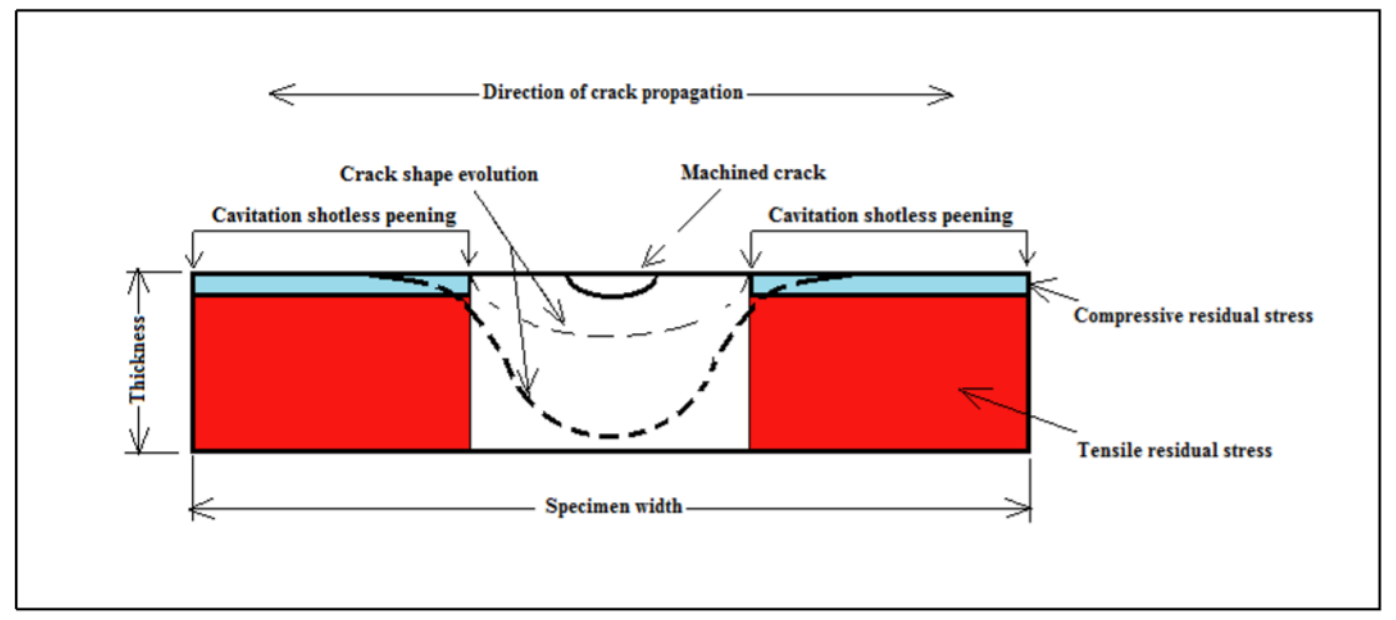

Figure 19: Schematic diagram for the a cross section of the specimen 